\title{
Concepções de futuros professores a respeito da Educação Inclusiva e Educação Especial
}

\author{
Carla Cristina Marinho* \\ Sadao Omote**
}

\section{Resumo}

$\mathrm{Na}$ relação ensino-aprendizagem, as variáveis pessoais do professor precisam ser consideradas, pois a aprendizagem do aluno é determinada também pela qualidade da relação interpessoal entre eles. Portanto, o processo de formação do professor precisa ser capaz de lidar com tais características psicossociais do professor, levando-o a refletir sobre elas e eventualmente modifica-las para favorecer a aprendizagem. Há muitas variáveis que podem afetar o bom desempenho do professor. Neste artigo, são analisadas e discutidas as concepçôes de futuros professores a respeito da Educação Inclusiva e Educação Especial, considerando que tais concepçóes podem afetar profundamente a natureza das ações pedagógicas desenvolvidas pelo professor na sua relação com alunos com diferentes características, incluindo aqueles que apresentam diferenças ou dificuldades especiais. A partir das análises, concluímos que, ao menos no que concerne às concepçôes que foram avaliadas, o conhecimento teórico e prático apresentado pelos docentes, por intermédio da matriz curricular do curso de Pedagogia da UNESP de Marília, parece ter exercido algum efeito nas concepçóes dos estudantes do referido curso. Significa que as temáticas relacionadas à Educação Inclusiva e à Educação Especial podem estar sendo devidamente discutidas durante o processo de formação inicial desses estudantes, possibilitando-lhes apresentar concepções sobre Educação Inclusiva e Educação Especial coerentes com a legislação vigente e com a proposta desse curso de Pedagogia.

Palavras-chave: Concepçôes; Educação Inclusiva; Educação Especial.

\footnotetext{
* Mestre em Educação pela Universidade Estadual Paulista Júlio de Mesquita Filho, Marília, São Paulo, Brasil.
}

** Professor doutor da Universidade Estadual Paulista Júlio de Mesquita Filho, Marília, São Paulo, Brasil. 


\section{Conceptions of future teachers regarding Inclusive Education and Special Education}

\section{Abstract}

In the relationship teaching-learning, the teacher's personal variables need to be considered, for the student's learning is also determined by the quality of the interpersonal relationship between them. Therefore, the process of the teacher's formation needs to deal with psychosocial characteristics of the teacher, allowing him to ponder over them and eventually modify them to promote the student learning. There are many variables that can affect the teacher's performance. In this article, the future teachers' conceptions regarding the Inclusive Education and Special Education are analyzed and discussed, considering that such conceptions can affect the nature of the pedagogic actions developed by the teacher in their relationship with students with different characteristics, including those presenting differences or special difficulties. From the analyses, we believe that, at least in relation to the conceptions that were evaluated, the theoretical and practical knowledge presented by teachers, through the curriculum of the course of Pedagogy at São Paulo State University (UNESP) at Marília, seems to have had some effect on the students' conceptions. It means that the themes related to the Inclusive Education and the Special Education may have been discussed properly during the process of those students' initial formation, allowing them to present conceptions about Inclusive Education and Special Education in accordance to the legislation and to the proposal of that course of Pedagogy.

Keywords: Conceptions; Inclusive Education; Special Education.

\section{Introdução}

No processo de ensino e aprendizagem, a qualidade da relaçáo interpessoal entre professor e aluno apresenta-se como um dos fatores essenciais para o favorecimento do aprendizado. Em tal processo, variáveis pessoais do professor precisam ser consideradas, visto que podem influenciar práticas pedagógicas ${ }^{1}$ direcionadas aos alunos com diferentes características, incluindo aqueles que apresentam diferenças ou dificuldades especiais.

Com base nisso, alguns pesquisadores têm-se dedicado à realização de estudos sobre a compreensão de Educaçáo Inclusiva por parte de professores que atuam em salas de ensino comum. Nesses estudos, foram encontradas diferentes concepçóes sobre Educação Inclusiva, tais como o compartilhamento de um mesmo espaço físico por crianças com necessidades educacionais especiais junto às demais crianças (CAPELLINI; FONSECA, 2010; CHEQUETTO; ALMEIDA; GONÇALVES, 2014; PEDROSO, 2012; SANT'ANA, 2005; SANTOS; PACCINI, 2014; VICTOR, 2008); um direito de todos, bem como um valor a ser buscado (BARTALOTTI et al., 2008); e a oferta de educação de qualidade sem excluir nenhum aluno (ANDRADE, 2005). 
As diferentes concepções de Educação Inclusiva mencionadas anteriormente são indicativos de que tal conceito encontra-se em processo de significação. Além disso, revelam que parte dos professores que atuam em salas de ensino comum não apresenta intelecção sobre o princípio político, filosófico e ideológico da Educação Inclusiva, bem como sobre o seu papel político, pedagógico e social com respeito à educação da diversidade do alunato, inclusive de alunos público-alvo da Educação Especial $^{2}$.

Diante disso, cabe a indagação sobre qual seria, particularmente para os professores que atuam em salas de ensino comum, o lugar da Educação Especial, em um contexto educacional orientado pela proposta da Educação Inclusiva, visto que, nas últimas décadas, foram realizados intensos debates sobre a inclusão escolar que culminaram em mudanças referentes à atuação da Educação Especial em face da educação de alunos com deficiências, transtornos globais do desenvolvimento e altas habilidades/superdotação.

No passado, pedagogos com habilitação em Educação Especial eram incumbidos da escolarização de alunos com deficiência. Atualmente, são os pedagogos e os professores formados nas demais licenciaturas os responsáveis pela escolarização desses alunos em salas de ensino comum. Esses profissionais da educaçáo devem possuir competências para perceber as necessidades educacionais especiais dos alunos que constituem o público-alvo da Educação Especial, flexibilizar a ação pedagógica em diferentes áreas de conhecimento, avaliar continuamente a eficácia do processo educativo e atuar em equipe com professores especializados em Educação Especial (BRASIL, 2001).

A partir dessa constatação, podemos perceber que o conceito de Educação Especial encontra-se em processo de ressignificação, o qual parece tentar acompanhar - por meio do atendimento da atual demanda - a progressiva construção e consolidação da Educação Inclusiva.

Foram executadas, ao longo desse processo, práticas de reclusão familiar e institucional, que podem ser talvez consideradas algumas das primeiras práticas de acolhimento e atendimento formal prestado às pessoas com deficiências (ARANHA, 2001; BIANCHETTI, 1998; MAIA, 2007; OMOTE, 2008, 2013; PESSOTI, 1984); práticas de atendimento educacional disponíveis exclusivamente em escolas especiais e classes especiais; práticas de atendimento educacional especializado com o intuito de integrar as pessoas com deficiências em salas de ensino comum, por intermédio de seu treinamento e capacitação; e, nas últimas décadas, práticas de atendimento educacional especializado com o objetivo de oferecer suporte às pessoas com deficiências, transtornos globais do desenvolvimento e altas habilidades/superdotação, a fim de que permaneçam na sala de ensino comum devidamente escolarizadas e, apenas excepcionalmente, em serviços educacionais especiais segregados (ARANHA, 2001; GLAT; FERNANDES, 2005; MENDES, 1995, 2006; OMOTE, 2008, 2013).

A despeito do processo de evolução histórica dos conceitos de Educação Especial e Educação Inclusiva - constatada mediante progressiva mudança das formas de organização de serviços educacionais direcionados ao público-alvo da Educação Es- 
pecial -, as práticas pedagógicas desenvolvidas em parte das escolas de ensino comum permanecem pobres e restringem-se ao atendimento das necessidades educacionais especiais dessa população.

O aumento das oportunidades de acesso à educação em escolas brasileiras de ensino comum está efetivando-se desacompanhado da melhoria da organização e funcionamento dos Sistemas Educacionais e de Ensino, das condiçóes de trabalho, de jornada, de formação e valorização do professor, fatores que, desajustados nesse contexto, certamente contribuem para a manutenção de uma escola excludente (LIBÂNEO; PIMENTA, 1999).

Em oposição à exclusão e/ou inclusão escolar precária de alunos pertencentes às populaçóes marginalizadas ${ }^{3}$, dentre as quais estão os alunos público-alvo da Educação Especial, é urgente o investimento em políticas públicas efetivas, disponibilização de materiais, recursos e estrutura física adequada, além da valorização e incentivo aos professores (VIEIRA, 2014).

A esses profissionais da educação, é preciso oferecer salários e condiçôes de trabalho dignos, assim como possibilitar-lhes, desde a formação inicial, a apropriação de "[...] perspectivas de análise que os ajudem a compreender os contextos históricos, sociais, culturais, organizacionais nos quais se dá sua atividade docente e pedagógica [...]" (LIBÂNEO; PIMENTA, 1999, p. 261), bem como o domínio de fundamentos educacionais, metodologias de ensino e também de conhecimentos teóricos e práticos sobre as necessidades específicas de alunos público-alvo da Educação Especial (FONSECA-JANES, 2010).

Para além disso, no processo de formação inicial de professores, sem dúvida, será preciso mais que disseminar ensinamentos sobre a educação na diversidade $\mathrm{e}$ prover experiências práticas de ensino inclusivo (OMOTE, 2001). Futuros professores devem ser devidamente conduzidos para que realizem reflexóes e indagaçóes constantes a respeito de suas concepçôes, seus valores, suas atitudes e os efeitos destas sobre seus alunos.

O processo de formação, portanto, precisa ser capaz de lidar com características psicossociais de futuros professores, tais como suas concepçôes sobre Educação Inclusiva e Educação Especial, levando-os a refletirem sobre elas e eventualmente modifica-las em conformidade com as demandas efetivas do processo de ensino e aprendizagem.

\section{Educação Inclusiva e Educação Especial: o que pensam futuros professores?}

Em virtude do destaque dado às variáveis pessoais de futuros professores no processo de inclusáo escolar, parece-nos relevante apresentar alguns estudos realizados sobre suas concepçóes a respeito da Educação Inclusiva e Educação Especial. De modo geral, os resultados evidenciam concepçóes pautadas no senso comum, ausência de clareza sobre o conceito de Educação Inclusiva e de Educação Especial, bem como a necessidade de, no processo de formação inicial, realizarem-se discussóes aprofundadas sobre as temáticas que envolvem os dois conceitos. 
Rosa e Silva (2008) indicaram que estudantes do $3^{\circ}$ ano de Pedagogia do Centro Universitário de Araraquara, antes de cursarem a disciplina "Educação e Inclusão", compreendiam a Educação Inclusiva como direito ou lei. Para os estudantes de Pedagogia, os alunos pertencentes ao público-alvo da Educação Especial deveriam estar inseridos em salas de ensino comum para terem acesso a oportunidades de convivência.

Os estudantes de Pedagogia, da Universidade Federal do Espírito Santo, do $2^{\circ}$ ao $4^{\circ}$ anos, após terem cursado a disciplina "Introdução à Educação Especial", conceberam a Educação Especial como disciplina voltada especificamente para alunos com necessidades educacionais especiais. Esses estudantes de Pedagogia mencionaram que todos os alunos, sem exceção, apresentam necessidades educacionais especiais e, portanto, precisam de uma Educação Especial, considerando-a expressão com significado igual ao da Educação Inclusiva (SILVA; MAFEZONI; COSTA, 2012).

Dos 202 estudantes ingressantes dos cursos de Pedagogia da UNESP, investigados por Fonseca-Janes (2010), quatro (2\%) identificaram o conceito de Educação Inclusiva como sinonímia da expressão Educação Especial, 70 (35\%) descreveram como sinonímia da expressão inclusão escolar, $81(40 \%)$ entenderam como sinonímia da expressão inclusão escolar de pessoas com deficiência, $10(5 \%)$ compreenderam como sinonímia da expressão educação de qualidade e 37 (18\%) descreveram de modo não pertinente. Ainda dentre os 202 estudantes de Pedagogia, 4 (2\%) conceberam a Educação Especial como sinonímia da expressão Educação Inclusiva, 84 (42\%) consideraram como modalidade educacional específica, 31 (15\%) descreveram como modalidade de ensino transversal, 28 (14\%) como modalidade educacional excludente e $55(27 \%)$ caracterizaram de modo não pertinente. A autora relatou que a formação dos estudantes, ao longo dos quatro anos de curso de Pedagogia, poderia mudar a compreensão deles sobre os dois conceitos.

Entre os 60 estudantes do $4^{\circ}$ ano de Pedagogia da UNESP de Marília, a concepção de Educação Inclusiva como sinonímia da expressão educação de qualidade e a concepção de Educação Especial como modalidade de ensino transversal foram as que tiveram maior destaque entre os estudantes. Pode-se sugerir que os dois conceitos em questão estão passando por um processo de ressignificação teórica, a qual está sendo possibilitada pelas lutas promovidas por movimentos sociais, pela legislação, pela disseminação do assunto por intermédio da mídia e pelas discussóes realizadas durante o processo de formação inicial de professores (MARINHO, 2013; MARINHO; OMOTE, 2016).

$\mathrm{Na}$ formação inicial de professores, o desafio é mudar as concepções dos estudantes sobre Educação Inclusiva e Educação Especial amparadas no senso comum, para que possam orientar práticas pedagógicas capazes de promover ensino de qualidade a todos os alunos.

Para que se altere o discurso de senso comum sobre a Educação Inclusiva e Educação Especial, é necessário que "[...] novos discursos sejam incorporados, o que envolve uma conscientização por parte dos falantes, das diferentes formas de discurso e suas implicações" (MENDES, 2001, p. 56). 
No contexto acadêmico, o conhecimento teórico e prático apresentado aos futuros professores pode ter relação com as concepçôes deles sobre Educação Inclusiva e Educação Especial.

A fim de verificar tal hipótese, realizamos estudo com estudantes do $1^{\circ}$ e $4^{\circ}$ anos de Pedagogia da UNESP de Marília, instituição que possui longa trajetória histórica na formação de pedagogos especializados em Educação Especial e que, atualmente, vem se esforçando para formar pedagogos para a atuaçáo docente na Educação Infantil, Ensino Fundamental e para a Gestão de Sistemas Educacionais e de Ensino, a partir de uma perspectiva inclusiva.

Com a finalidade de preparar seus estudantes para, no futuro, receberem em suas salas de aulas alunos com deficiências, transtornos globais do desenvolvimento e altas habilidades/superdotação, esse curso de Pedagogia oferece uma matriz curricular que contempla amplamente as temáticas da Educação Inclusiva e Educação Especial, bem como oferta o aprofundamento em Educação Especial, no último semestre do curso, quando os estudantes fazem opçáo pela área na qual pretendem fazer o seu aprofundamento ${ }^{4}$.

A matriz curricular desse curso compreende várias disciplinas de Educação Inclusiva e Educaçáo Especial. No tronco comum, entre o primeiro semestre do $1^{\circ}$ ano e primeiro semestre do $4^{\circ}$ ano, são oferecidas cinco disciplinas obrigatórias perfazendo 270 horas/aula e três disciplinas optativas com carga horária total de 135 horas/ aula. No Aprofundamento em Educação Especial, no segundo semestre do $4^{\circ}$ ano, são oferecidas cinco disciplinas obrigatórias com carga horária total de 300 horas/ aula. Portanto, todos os Pedagogos formados nesse curso têm de 270 a 405 horas/ aula e os que fazem Aprofundamento em Educação Especial, de 570 a 705 horas/aula de conteúdos relativos a Educação Inclusiva e Educação Especial.

Fizeram parte de nosso estudo 177 estudantes de Pedagogia da UNESP de Marília. Foi utilizada a Escala de Concepções acerca de Educação Inclusiva e Educação Especial. A escala contém 20 itens, sendo dez atinentes à concepção de Educação Inclusiva e dez atinentes à concepção de Educação Especial. Cada item é constituído por três enunciados com conteúdos que representam três categorias conceituais referentes à concepção de Educação Inclusiva ou de Educaçáo Especial. As categorias conceituais de Educação Inclusiva compreendem: sinonímia com a expressão inclusão escolar, sinonímia com a expressão inclusão escolar de pessoas com deficiência e sinonímia com a expressão educação de qualidade. As categorias conceituais de Educação Especial compreendem: modalidade educacional específica, modalidade de ensino transversal e modalidade educacional excludente.

$\mathrm{O}$ instrumento foi aplicado a 107 estudantes do $1^{\circ}$ ano no início do primeiro semestre e a 70 estudantes do $4^{\circ}$ ano no início do segundo semestre, isto é, início do aprofundamento em Educação Especial, aprofundamento em Educação Infantil e aprofundamento em Gestão em Educação.

Os resultados evidenciaram que, na comparação intragrupo, a concepção de Educação Inclusiva como sinonímia da expressão educação de qualidade e a de 
Educação Especial como modalidade de ensino transversal foram as concepções em destaque no $1^{\circ}$ e $4^{\circ}$ anos de Pedagogia. Entretanto, o grupo de estudantes do $1^{\circ}$ ano parece ter menos clareza sobre os dois conceitos em questáo, visto que, na comparação intergrupal, os escores deles referentes à concepção de Educaçáo Inclusiva como sinonímia da expressão inclusão escolar de pessoas com deficiência e de Educação Especial como modalidade educacional excludente foram significantemente maiores que os do $4^{\mathrm{o}}$ ano.

Este resultado pode ser decorrente do fato de os estudantes do $1^{\circ}$ ano não terem tido acesso aos conhecimentos teóricos e práticos ofertados em disciplinas que abordam as temáticas da Educação Inclusiva e da Educação Especial, constantes da matriz curricular do curso de Pedagogia da UNESP de Marília. No decorrer do curso, a concepção de Educação Inclusiva como educação de qualidade e a de Educação Especial como modalidade de ensino transversal parecem fortalecer-se.

A definição da Educação Inclusiva como inclusão escolar de pessoas com deficiência considera que ela "é igual ou a mesma coisa que a colocação de todas as pessoas com deficiência na escola” (FONSECA-JANES, 2010, p. 221). A inserçáo de alunos com deficiência em contextos escolares comuns junto aos demais alunos sem deficiência representaria a Educação Inclusiva.

É preciso ponderar que a Educação Inclusiva não deve ser compreendida como algo direcionado apenas à inserção de alunos com deficiência, como habitualmente vem acontecendo por parte de professores que atuam em escolas de ensino comum (CAPELLINI; FONSECA, 2010; CHEQUETTO; ALMEIDA; GONÇALVES, 2014; PEDROSO, 2012; SANT'ANA, 2005; SANTOS; PACCINI, 2014; VICTOR, 2008) e de estudantes ingressantes do curso de Pedagogia (FONSECA-JANES, 2010). Esse modo de conceber a Educação Inclusiva deve ser discutido no processo de formaçáo de futuros professores.

Já a predominância da concepção de Educação Inclusiva como educação de qualidade e da concepção de Educação Especial como modalidade de ensino transversal, no grupo de estudantes do $4^{\circ}$ ano de Pedagogia, demonstra que a proposta do curso de Pedagogia da UNESP de Marília está conseguindo atender parte do que se propóe a fazer para formar seus estudantes dentro de uma perspectiva inclusiva. A construção ou modificaçáo da compressão de dois conceitos fundamentais que podem influenciar positiva ou negativamente as práticas pedagógicas direcionadas aos alunos público-alvo da Educação Especial em salas de ensino comum parece estar sendo possibilitada pelos docentes desta unidade universitária mediante discussóes devidamente fundamentadas.

Conceber a Educação Inclusiva como sinonímia da expressão educação de qualidade é considerar que essa educação se destina a todas as crianças e jovens, independentemente de suas características (FONSECA-JANES; OMOTE, 2009). Portanto, a Educação Inclusiva deve ser compreendida a partir de pressupostos democráticos, em que o direito à educação pressupóe um ensino básico de qualidade para todos, não (re)produzindo mecanismos de diferenciação e de exclusão social (OLIVEIRA; ARAUJO, 2005). 
A lei que define e regulariza o sistema de educação brasileiro com base nos princípios presentes na Constituição, a Lei de Diretrizes e Bases (BRASIL, 1996), em seu artigo $4^{\circ}$, inciso IX, determina que o dever do Estado para a efetivaçáo do direito à educação é concretizado mediante a garantia de "padrôes mínimos de qualidade de ensino, definidos como a variedade e quantidade mínimas, por aluno, de insumos indispensáveis ao desenvolvimento do processo de ensino-aprendizagem”. Dessa forma, a Educação Inclusiva deve ser oferecida a todos os alunos independentemente de suas singularidades, considerando de modo articulado dimensôes como a socioeconômica e cultural dos sujeitos envolvidos, os direitos e obrigaçóes do Estado, condiçôes de oferta de ensino pelo sistema, gestão e organização do trabalho escolar, formação, profissionalização e ação pedagógica, e acesso, permanência e desempenho escolar do aluno (BRASIL, 2007).

Em um contexto educacional orientado pela proposta da Educação Inclusiva, a Educação Especial tem importante papel, visto que, concebida como modalidade de ensino transversal, tem a finalidade de assegurar um conjunto de recursos e serviços educacionais especiais, organizados institucionalmente para apoiar, complementar e suplementar os serviços educacionais comuns, de modo a garantir a educação escolar de alunos que apresentam necessidades educacionais especiais promovendo o desenvolvimento das potencialidades destes em todas as etapas e modalidades da educação básica (BRASIL, 2008).

O fato de a concepçáo de Educação Especial como modalidade educacional excludente destacar-se no grupo de estudantes do $1^{\circ}$ ano pode decorrer do fato de eles não terem tido acesso aos conhecimentos teóricos e práticos ofertados em disciplinas que abordam as temáticas da Educação Inclusiva e da Educação Especial existentes na matriz curricular do curso de Pedagogia da UNESP de Marília.

A concepção de Educação Especial como modalidade educacional excludente sugere uma modalidade de ensino direcionada aos alunos com deficiência, a qual serve de instrumento de legitimação da segregação desses alunos (BUENO, 1993). Conceber a Educação Especial como modalidade educacional excludente é defender a ideia de extinção dos serviços educacionais especializados em prol de uma inclusão escolar total em que os alunos independentemente do grau e tipo de incapacidade devem ser inseridos em salas de ensino comum. A perspectiva da inclusão escolar total baseia-se no pensamento de que os serviços oferecidos pela Educação Especial, organizados e disponibilizados em espaços segregados dos espaços comuns, é que promovem a segregação de seus usuários, conforme aponta Mendes (2006). Entretanto, o caráter segregativo ou inclusivo dos serviços ou recursos oferecidos pela Educação Especial pode depender fundamentalmente do modo como são utilizados (OMOTE, 1999a; 1999b).

Em nome de uma inclusão escolar total, também podem ser mantidos segregados e, portanto, à margem do processo de ensino e aprendizagem escolar, crianças e jovens severamente comprometidos que não tem condiçôes de serem escolarizados em salas de ensino comum por não conseguirem tirar proveito do que a escola tem a oferecer na atualidade (OMOTE, 2003). A eles devem ser oferecidos outros serviços 
de qualidade, de que necessitam, em outros ambientes, habitualmente fora das instituições educacionais convencionais.

Nesse contexto, além da preocupação com o oferecimento de uma Educação Inclusiva, isto é, de qualidade, para toda a diversidade do alunato, inclusive alunos público-alvo da Educação Especial, em salas de ensino comum, por intermédio, quando necessário, da oferta de suporte pedagógico especializado, deve-se também realizar atendimento educacional especializado em escolas especiais, classes hospitalares e em ambiente domiciliar aos alunos que, em funçáo de seu comprometimento, náo podem ser escolarizados em salas de ensino comum. Embora possa não ser confortável essa discussão, o profissional da área de Educação Especial não pode negligenciar a parcela de pessoas com deficiência com comprometimentos de tal ordem que simplesmente é insano pensar em oferecer qualquer rudimento de educaçáo escolar. Em vez disso, precisam de serviços de outra natureza, que a instituição escolar não pode oferecer. Não se restringem estritamente a serviços de saúde. Ainda que com grave comprometimento, precisam adquirir uma série de competências requeridas para construir uma melhor qualidade de vida.

Os resultados obtidos no nosso estudo sugerem que, ao menos no que concerne às concepçôes que foram avaliadas, o conhecimento teórico e prático apresentado pelos docentes, por intermédio da matriz curricular do curso de Pedagogia da UNESP de Marília, parece ter exercido algum efeito nas concepçóes dos estudantes do referido curso. As temáticas relacionadas à Educação Inclusiva e à Educação Especial podem estar sendo devidamente discutidas, durante o processo de formação inicial desses estudantes, possibilitando-lhes apresentar concepçôes sobre Educação Inclusiva e Educação Especial coerentes com a legislação vigente e com a proposta do curso. Esse curso tem como propósito formar pedagogos em uma perspectiva inclusiva, preparados para identificarem, acolherem e oferecerem respostas às necessidades educacionais especiais de alunos com deficiências, transtornos globais do desenvolvimento e altas habilidades/superdotação, com apoio de professores especializados em Educação Especial, no contexto educacional comum.

O Departamento de Educação Especial, ao qual cabe parcela de responsabilidade pelo curso de Pedagogia, ao oferecer conhecimentos teóricos e práticos sobre a Educação Inclusiva e a Educação Especial, em processos de formação inicial e continuada, mantém o compromisso com o investimento, na formação tanto do pedagogo de sala de ensino comum quanto do pedagogo que atua nos serviços de Educação Especial (GIROTO; POKER; MILANEZ, 2012). Esse curso parece oferecer condiçôes propícias para a parceria entre esses profissionais, a fim de que eles garantam a provisão de ensino de qualidade aos alunos público-alvo da Educação Especial, que requerem o uso de recursos diferenciados (materiais, equipamentos, métodos e técnicas etc.) em salas de ensino comum (FONSECA-JANES; OMOTE, 2013b).

Contudo, há de se ponderar que o oferecimento de disciplinas que contemplam conteúdos referentes à Educação Inclusiva e Educação Especial, ao longo dos semestres, não garante a qualidade da formação de pedagogos para a realização de práticas pedagógicas favoráveis à aprendizagem de alunos público-alvo da Educação 
Especial no contexto escolar comum, nem possibilita a articulação com as demais disciplinas oferecidas pelo curso. A particularização do tema Educação Inclusiva abordada em disciplinas isoladas, sem interação com outras disciplinas - e o reconhecimento demorado por parte das universidades brasileiras de que as escolas recebem há tempos alunos com características que influenciam suas condiçôes de aprendizagem, podem ser considerados algumas das hipóteses explicativas para a desarmonia dos elementos que compóem nossos Sistemas Educacionais e de Ensino (CRUZ; GLAT, 2014).

Apesar disso, é importante que o estudante de Pedagogia, ao frequentar disciplinas de estágio, de metodologia e prática de ensino, ou disciplinas que discutem aspectos sociológicos, filosóficos ou psicológicos da educação, tenha conhecimento dos conteúdos referentes à Educação Especial, a fim de levantar, durante as discussôes teóricas, questóes relevantes atinentes à Educação Inclusiva e aos alunos público-alvo da Educação Especial (DEIMLING; CAIADO, 2012).

Com a organização dessa matriz curricular, esperamos que o curso de Pedagogia da UNESP de Marília esteja formando seus estudantes para o domínio de conceitos como os de Educação Inclusiva e de Educação Especial e para o desenvolvimento de atitudes sociais genuinamente favoráveis à Inclusão, a fim de que eles se tornem acolhedores em relação às diferenças e diversidades existentes na sala de aula e exerçam práticas pedagógicas relativas à inclusão de alunos público-alvo da Educação Especial (FAINTANIN; COSTA; FERRAZ, 2009; FONSECA-JANES; OMOTE, 2013a; 2013b).

Mesmo com carga horária relativamente pequena, como é habitual nos cursos de Pedagogia no país, disciplinas que tratam de temas relacionados a inclusão podem exercer efeitos expressivos sobre as atitudes sociais e futuros pedagogos em relaçáo à inclusão (FONSECA-JANES; OMOTE, 2013a). A formaçẫo ou modificação dessas atitudes sociais pode ser uma das importantes diretrizes na organização curricular de cursos de Pedagogia.

\section{Referências}

ANDRADE, S. G. Açáo docente, formaçáo continuada e inclusáo escolar. 2005. 204 f. Tese (Doutorado em Educação) - Faculdade de Educação, Universidade Federal do Rio Grande do Sul, Rio Grande do Sul, 2005. Disponível em: <http://www.educadores.diaadia.pr.gov.br/arquivos/File/2010/artigos_teses/Pedagogia/tdocente_form_cont_inclusao.pdf>. Acesso em: 20 mar. 2015.

ARANHA, M. S. F. Paradigmas da relação da sociedade com as pessoas com deficiência. Revista do Ministério Público do Trabalho, v. 21, n. 21, p. 160-173, 2001. Disponível em: <http://www.adiron.com.br/arquivos/ paradigmas.pdf>. Acesso em: 20 mar. 2015.

BARTALOTTI, C.C et.al. Concepçóes de profissionais de educaçáo e saúde sobre educaçáo inclusiva: reflexões para uma prática transformadora. O Mundo da Saúde, São Paulo, v.32, n.2, p.124-130, 2008. Disponível em: <http://saocamilo-sp.br/pdf/mundo_saude/59/124a130.pdf>. Acesso em: 20 mar. 2015.

BIANCHETTI, L. Aspectos históricos da apreensão e da educaçáo dos considerados deficientes. In: BIANCHETTI, L.; FREIRE, I. M. Um olhar sobre a diferença: interação, trabalho e cidadania. Campinas: Papirus, 1998. p. 21-51.

BRASIL. Lei no 9.394, de 20 de dezembro de 1996. Estabelece as diretrizes e bases da educaçáo nacional. Brasília, DF.: MEC, 1996. Disponível em: <http://www.planalto.gov.br/ccivil_03/Leis/L9394.htm>. Acesso em: 20 mar. 2015. 
Ministério da Educação. A qualidade da educaçáo: conceitos e definiçôes. Brasília, DF.: INEP/MEC, 2007. Disponível em: <http://escoladegestores.mec.gov.br/site/8 blioteca/pdf/qualidade_da_educacao.pdf>. Acesso em: 20 mar. 2015.

Ministério da Educação. Conselho Nacional de Educação. Câmara de Educação Básica. Resoluçáo CNE/CEB n. 2, de 11 de setembro de 2001. Institui Diretrizes Nacionais para a Educação Especial na Educação Básica. Diário Oficial da Uniāo, Brasília, DF., 14 de setembro de 2001. Seçāo 1E. p. 39-40. Disponível em: <http://portal.mec.gov.br/cne/arquivos/pdf/CEB0201.pdf>. Acesso em: 20 mar. 2015.

. Ministério da Educação. Secretaria de Educação Especial. Diretrizes operacionais da educaçáo especial para o atendimento educacional especializado na educaçáo básica. Brasília, DF.: MEC/SEESP, 2008. Disponível em: < file:///C:/Users/Carla/Downloads/diretrizes_publicacao.pdf>. Acesso em: 20 mar. 2015.

BUENO, J. G. S. Educação Especial no Brasil. In: ção do aluno deficiente. São Paulo: EDUC, 1993. p. 85-141.

Educaçáo Especial Brasileira: integração/segrega-

CAPELLINI, V. L. M. F.; FONSECA, K. A. Perfil e concepçôes sobre educação inclusiva de uma equipe escolar participante de um programa de formação continuada por meio da consultoria colaborativa. In: CBEE - Encontro Nacional de pesquisadores em Educação Especial, 4, 2010, São Carlos. Anais... São Carlos, 2010. p. 1-16.

CHEQUeTTO, J. J.; ALMEIDA, M. B.; GONÇALVES, A. F. S. Um estudo com professores do Ensino Médio acerca da Educação Inclusiva e Educação Especial. In: Seminário Nacional de Educação Especial, 3.; Seminário Capixaba de Educação Inclusiva, 14., 2014, Vitória. Anais... Vitória: UFES, 2014. p. 1-18.

CRUZ, G. C.; GLAT, R. Educaçáo inclusiva: desafio, descuido e responsabilidade de cursos de licenciatura. Educar em Revista, Curitiba, n. 52, p. 257-273, abr./jun. 2014.

DAMIS, O. T. Didática e Sociedade: o conteúdo implícito do ato de ensinar. In: VEIGA, I. P. A. (Org.). Didática: o ensino e suas relaçôes. Campinas: Papirus, 1996, p. 9-31.

DEIMLING, N. N.; CAIADO, K. R. M. C. Formação de professores para a educação inclusiva nos cursos de pedagogia das universidades públicas paulistas. Rev. Teoria e Prática da Educaçáo, Maringá, v. 15, n. 3, p. 51-64, set./dez., 2012.

FAITANIN, G. P. S.; COSTA, V. A.; FERRAZ, V. Formação e Educação Inclusiva: as concepçôes do curso de Pedagogia/UFF à luz das atuais políticas públicas. In: Congresso brasileiro multidisciplinar de Educação Especial, 5, 2009, Londrina. Anais... Londrina: UEL, 2009. p. 1540-1549.

FONSECA-JANES, C. R. X. A formaçáo dos estudantes de pedagogia para a educaçáo inclusiva: estudo das atitudes sociais e do currículo. 2010. 269 f. Tese (Doutorado em Educação) - Faculdade de Filosofia e Ciências, Universidade Estadual Paulista - Unesp, Marília, 2010.

; OMOTE, S. Atitudes sociais em relaçáo à inclusão mantidas por estudantes de um curso de pedagogia da Universidade Estadual Paulista: primeira análise. In: Congresso brasileiro multidisciplinar de Educação Especial, 5, 2009, Londrina. Anais... Londrina: UEL, 2009.

Atitudes sociais em relação à inclusão: o curso de Pedagogia da Faculdade de Ciências e Tecnologia da UNESP. In: Nuances: estudos sobre Educação. Presidente Prudente, SP, v. 24, p. 158-173, 2013a. Disponível em: <http://revista.fct.unesp.br/index.php/Nuances/article/view/2486>. Acesso em: 27 mar. 2015.

. Os cursos de Pedagogia da Universidade Estadual Paulista e a Educaçăo Inclusiva. Rev. Bras. Ed. Esp., Marília, SP, v. 19, n. 3, p. 325-342, jul./set., 2013b.

GIROTO, C. R. M.; POKER, R. B.; MILANEZ, S. G. C. Perspectiva da Educaçấo Inclusiva: algumas contribuiçóes do Departamento de Educação Especial da FFC. In: BRABO, T. S. A. M.; CORDEIRO, A. P.; MILANEZ, S. G. C. (Org.). Formação da Pedagoga e do Pedagogo: pressupostos e perspectivas. Marília: Oficina Universitária, São Paulo: Cultura Acadêmica, 2012, p.181-193.

GLAT, R.; FERNANDES, E. M. Da segregação à educação inclusiva: uma breve reflexão sobre os paradigmas educacionais no contexto da Educação Especial brasileira. Inclusáo, Brasília, DF, v. 1, n.1, p. 35-39, 2005. Disponível em: <http://pt.static.zdn.net/files/d74/5747c95d4320a44b5132153887c3c17c.pdf>. Acesso em: 27 mar. 2015.

LIBÂNEO, J. C. Pedagogia e Pedagogos, para quê?. 12. ed. São Paulo, Cortez, 2010.

LIBÂNEO, J. C.; PIMENTA, S. G. Formaçẫo de profissionais da educação: visão crítica e perspectiva de mudança. Educaçáo e Sociedade, n. 68, p. 239-277, 1999. Disponível em: <http://www.scielo.br/pdf/es/v20n68/ a13v2068.pdf>. Acesso em: 08 mar. 2015. 
MAIA. J. C. Concepçóes de deficiência mantidas por discentes de Terapia ocupacional e Fisioterapia. 2007. 58 f. Trabalho de Conclusão de Curso (Graduação em Terapia Ocupacional) - Faculdade de Filosofia e Ciências, Universidade Estadual Paulista - Unesp, Marília, 2007.

MARINHO, C.C. Concepçóes de estudantes de Pedagogia acerca de educaçáo inclusiva e educaçáo especial. 164 f. 2013. Trabalho de Conclusão de Curso (Licenciatura em Pedagogia) - Faculdade de Filosofia e Ciências, Universidade Estadual Paulista - Unesp, Marília, 2013.

MARINHO, C.C.; OMOTE.S. Concepçôes: Educação Inclusiva e Educação Especial. Journal of Research in Special Educational Needs, v. 16, p. 313-317, 2016.

MENDES, E. G. A radicalização do debate sobre inclusão escolar no Brasil. Revista de Brasileira de Educaçáo, Rio de Janeiro, v. 11, n. 33, p. 387-405, 2006. Disponível em: http://www.scielo.br/pdf/rbedu/v11n33/ a02v1133.pdf >. Acesso em: 27 mar. 2015.

Deficiência Mental: a construção científica de um conceito e a realidade educacional. 1995. 387 f. Tese (Doutorado em psicologia) - Instituto de Psicologia, Universidade de São Paulo, São Paulo, 1995.

Reconstruindo a concepção deficiência na formação de recursos humanos em educação especial. In: MARQUEZINE, M. C.; ALMEIDA, M. A.; TANAKA, E. D. O. (Org.). Perspectivas multidisciplinares em educaçáo especial II. Londrina: Ed. UEL, 2001, p. 53-64.

OLIVEIRA, R. P.; ARAUJO, G. C. A. Qualidade do ensino: uma nova dimensão da luta pelo direito à educaçấo. Revista Brasileira de Educaçáo, Poços de Caldas, MG, n. 28, p. 5-23, 2005. Disponível em: <http://www. scielo.br/pdf/rbedu/n28/a02n28.pdf $>$. Acesso em: 17 jul. 2011.

OMOTE, S. A concepção de deficiência e a formaçáo do profissional em educaçáo especial. In: MARQUEZINE, M. C.; ALMEIDA, M. A.; TANAKA, E. D. O. (Org.). Perspectivas multidisciplinares em educaçáo especial II. Londrina: Editora UEL, 2001. p. 45-52.

A formação do professor de Educação Especial na perspectiva da inclusão. In: BARBOSA, R.L.L. (Org). Formaçáo dos Educadores: desafios e perspectivas. São Paulo: Editora UNESP, 2003, p. 153-169.

Deficiência: da diferença ao desvio. In: MANZINI, E.J., BRANCATTI, P.R. (Org.) Educaçáo Especial e Estigma: corporeidade, sexualidade e expressão artística. Marília: CAPES/UNESP-Marília Publicaçôes, 1999a, p. 3-21.

Diversidade, educação e sociedade inclusiva. In: OLIVEIRA, A. A. S.; OMOTE, S.; GIROTO, C. R. M. (Org.). Inclusáo escolar: as contribuiçōes da educação especial. São Paulo: Cultura acadêmica, 2008, p. $15-32$.

El futuro de la atención a la diversidad. In: HEREDERO, E.S.; GIROTO, C.R.M.; MARTINS, S.E.S.O. (Ed.). La Formación del Professorado para la Atención a la Diversidad en Brasil y Espana. Alcalá de Henares: Servicio de Publicaciones de la UAH, 2013, p. 199-218.

Normalização, integração, inclusão... Ponto de Vista, v. 1, n. 1, p. 4-13, 1999 b.

PEDROSO, S. R. S. As concepçóes de Educaçáo Especial e Inclusáo Escolar de professores da Educaçáo Infantil do I ciclo de uma escola de ensino fundamental comum da rede municipal de ensino de Porto Alegre. 2012. 36 f. Trabalho de conclusão de Curso (Especialização em Educação Especial e Inclusão Escolar) Faculdade de Educaçáo, Universidade Federal do Rio Grande do Sul, Porto Alegre, 2012.

PESSOTTI, I. Deficiência mental: da superstição à ciência. São Paulo: EDUSP, 1984.

ROSA, J. C. L.; SILVA, C. R. Percepçôes sobre a educaçáo inclusiva em um curso de graduação em pedagogia: reflexôes e propostas para a formação de professores. In: Congresso brasileiro de Educação Especial; Encontro Nacional de pesquisadores da Educação Especial, 5, 2008, São Carlos. Anais... São Carlos: Universidade Federal de São Carlos, 2008. p. 1-10.

SANT'ANA, I. M. Educação inclusiva: concepçôes de professores e diretores. Psicologia em Estudo, Maringá, v. 10, n. 2, p. 227-234, mai./ago. 2005. Disponível em: < http://www.scielo.br/pdf/\%0D/pe/v10n2/v10n2a09. pdf>. Acesso em: 27 mar. 2015.

SANTOS, W. M., PACCINI, J. V. Percepção de profissionais da educação: inclusão escolar e capacitação profissional em análise. In: Seminário de Educação Especial, 3; Seminário capixaba de Educação Inclusiva, 14, 2014, Vitória. Anais... Vitória: UFES, 2014. p. 1-8.

SILVA, F. N. G.; MAFEZONI, A. C.; COSTA, C. R. R. A formaçâo inicial de professores e a perspectiva de inclusão escolar de alunos com deficiência: o entendimento dos alunos do curso de pedagogia sobre a educaçáo especial. In: Congresso de Educaçáo no Brasil, 5; Eencontro nacionaol dos pesquisadores da Educaçáo Especial, 7, 2012, São Carlos. Anais... São Carlos: UFSCar, 2012. p. 5841- 5854.

UNESCO. Declaraçáo de Salamanca e linha de açáo sobre necessidades educativas especiais. Brasília, DF: CORDE, 1994. 
VICTOR, S. L. Inclusão Escolar de crianças com necessidades educacionais especiais na educação infantil: concepçôes de professoras regentes e especialistas em educação especial. In: Seminário capixaba de Educaçấo Inclusiva, 11, 2008, Vitória. Anais... Vitória: Editora PPGE/UFES, 2008. p. 01-14.

VIEIRA, C. M. Atitudes sociais em relação à inclusão: efeitos da capacitação de professores para ministrar programa informativo aos alunos. 2014. 184f. Tese (Doutorado em Educaçáo) - Faculdade de Filosofia e Ciências, Universidade Estadual Paulista - Unesp, Marília, 2014.

\section{Notas}

${ }^{1}$ Compreendemos a prática pedagógica como pratica social orientada por "[...] conhecimentos científicos, filosóficos e técnico-profissionais, [...] tendo em vista objetivos de formação humana definidos em sua contextualização histórica" (LIBÂNEO, 2010, p. 51-52), os quais podem contribuir para a manutençăo ou superaçăo da prática social mais ampla (DAMIS, 1996).

${ }^{2}$ Alunos com deficiências, transtornos globais do desenvolvimento e altas habilidades/superdotaçáo, segundo a legislação brasileira atual, são considerados público-alvo da Educação Especial (BRASIL, 2008).

${ }^{3}$ Alunos pertencentes às populaçôes marginalizadas são os que historicamente têm sido excluídos da escola ou mantidos nela em situação segregativa. Trata-se, conforme explicitado na Declaraçấo de Salamanca, "[...] de crianças deficientes e superdotadas, crianças de rua e que trabalham, crianças de origem remota ou de populaçáo nômade, crianças pertencentes a minorias linguísticas, étnicas ou culturais, e crianças de outros grupos em desvantagem ou marginalizados" (UNESCO, 1994, p.3).

${ }^{4}$ A matriz curricular do Curso de Pedagogia da UNESP de Marília oferece disciplinas relacionadas à Educação Inclusiva e Educaçáo Especial, distribuídas ao longo dos primeiros três anos e meio de curso. Aos estudantes interessados em aprofundar os conhecimentos, em áreas como Educaçáo Especial, Educação Infantil e Gestão em Educação, são ofertados aprofundamentos, no segundo semestre do $4^{\circ}$ ano.

\section{Correspondência}

Carla Cristina Marinho - Universidade Estadual Paulista, Faculdade de Filosofia e Ciências, Campus de Marília. Av Hygino Muzzi Filho, 737, Campus Universitário. CEP: 17525900. Marilia, São Paulo, Brasil.

E-mail:carla_cmarinho@hotmail.com - somote@uol.com.br

Recebido em 11 de julho de 2017

Aprovado em 11 de agosto de 2017 
